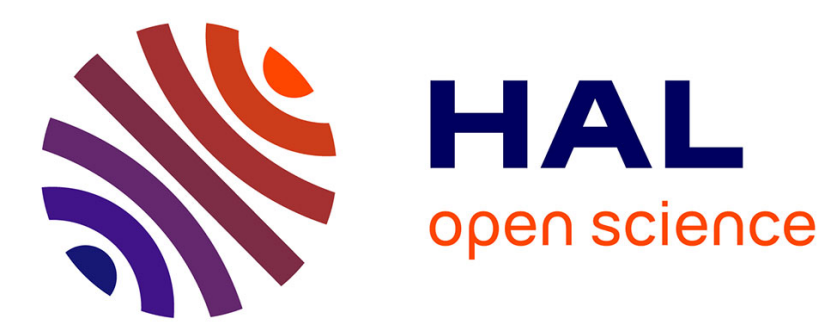

\title{
First-Degree Discrimination by a Duopoly: Pricing and Quality Choice
}

\author{
David Encaoua, Abraham Hollander
}

\section{To cite this version:}

David Encaoua, Abraham Hollander. First-Degree Discrimination by a Duopoly: Pricing and Quality Choice. The Berkeley Electronic Journal of Theoretical Economics, 2007, 7 (1), pp.Article 14. halshs00177604

\section{HAL Id: halshs-00177604 https://shs.hal.science/halshs-00177604}

Submitted on 10 Oct 2007

HAL is a multi-disciplinary open access archive for the deposit and dissemination of scientific research documents, whether they are published or not. The documents may come from teaching and research institutions in France or abroad, or from public or private research centers.
L'archive ouverte pluridisciplinaire HAL, est destinée au dépôt et à la diffusion de documents scientifiques de niveau recherche, publiés ou non, émanant des établissements d'enseignement et de recherche français ou étrangers, des laboratoires publics ou privés. 


\title{
First-Degree Discrimination in a Duopoly: Pricing and Quality
}

\section{Choice}

\author{
David ENCAOUA (Panthéon Sorbonne Economie, Paris School of \\ Economics, Université Paris I) \\ and \\ Abraham HOLLANDER (Université de Montréal) \\ Revised October 2006
}

\section{Abstract:}

The paper asks under what conditions vertically differentiated duopolists engage in first-degree price discrimination. Each firm decides first on a pricing regime and subsequently sets prices. The paper shows that when unit cost is an increasing and convex function of quality the discriminatory regime is a subgame-perfect equilibrium of the two-stage game. This is true for a very general distribution of consumer preferences. In contrast to the case of horizontal differentiation, the equilibrium is not necessarily Pareto-dominated by a bilateral commitment to price uniformly. The paper also shows that the qualities chosen by perfectly discriminating duopolists are welfare maximizing. It explains finally why a threat of entry may induce an incumbent monopolist to engage in price discrimination.

Key words: personalized pricing, vertical differentiation.

JEL Classification: L1, L12 


\section{Introduction}

Until recently, economists viewed first-degree discrimination as a theoretical construct without real world applications. The primary reason was that sellers did not possess information about the reservation prices of individual buyers. Unsurprisingly, the literature on first-degree-discrimination remained scarce. A notable exception arose in spatial economics. Because the distance is can be observed and because it correlates with transportation cost, the spatial economics literature often assumed that the mill price a seller could charge a buyer increased with the distance that separated him from that buyer (Hurter and Lederer, 1985, Lederer and Hurter, 1986, Thisse and Vives, 1988, Hamilton and Thisse, 1992, Ulph and Vulkan, 2000, 2001, Bhaskar and To, 2004).

Perceptions about the practicality of first-degree-discrimination have changed along with advances in information gathering/processing techniques and the spread of computer-mediated transactions. (Shapiro and Varian, 1999, Varian, 2003). These developments have spawned a literature that explores how on-line sellers with market power exploit information about consumer preferences through personalization of prices and product specifications (Fudenberg and Tirole, 2000, Acquisti and Varian, 2001, Varian, 2003). ${ }^{1}$

The improved capacity to gather and process information has also influenced pricing in traditional trading environments. Personalized discounting has become common at the check-out counter as sellers tailor promotional offers according to current purchases. ${ }^{2}$ Financial institutions also engage in personalization when they customize offers to individuals' financial ability and payment history. Journal publishers use information to adapt on-line subscription fees to the characteristics of individual academic libraries. ${ }^{3}$

A particular form of personalized pricing takes place in aftermarkets where firms earn high margins selling replacement parts whose wear and tear increase with intensity of use. ${ }^{4}$ And, in markets where intellectual prop-

\footnotetext{
${ }^{1}$ The terms "personalized pricing" and "first-degree price discrimination" are used interchangeably. First-degree price discrimination as used by Pigou(1920) refers to pricing that takes place when full information about consumers' demand is available and allows sellers to tailor prices to individual consumers. It does not necessarily describe a situation where all consumer surplus is captured by the producer(s) (See Stole, 2003).

${ }^{2}$ Some of the techniques used in online retailing are described at http://www.accenture.com/Global/Services/Accenture_Technology_Labs/R_and_I/PersonalizedPricingTool.htm

${ }^{3}$ See Edlin and Rubinfeld (2004)

${ }^{4}$ See e.g. Emch (2003)
} 
erty is licensed, personalized pricing did not await the emergence of on-line technologies. Royalties have traditionally depended on intensity of use.

Clearly, sellers' capacity to engage in personalized pricing depends on their ability to restrict reselling by first buyers. To limit reselling, software producers sell a non-transferable right to use their products; they do not sell the products.

Personalization of prices requires that sellers' costs not increase too fast as the number of price categories expands. On-line technologies are valuable in this regard as well because they facilitate customization in the absence of face-to-face contact.

The combined effect of these developments is to allow a form of pricing that approaches first-degree price discrimination. First-degree price discrimination remains a limiting case. In some market though actual pricing to is much to first-degree discrimination than in the past.

The paper examines personalized pricing in a market served by a quality differentiated duopoly. It addresses four questions. (1) What are the properties of a non-cooperative equilibrium in which each duopolist sets a perfectly discriminating price schedule? (2) Under what conditions would firms prefer to engage in personalized pricing if they had the means to enforce an agreement to price uniformly? (3) Does first-degree price discrimination perform better in terms of consumer surplus and global welfare than uniform pricing? (4) How do the quality choices of perfectly discriminating duopolists measure up in terms of welfare?

The paper addresses these questions in a framework similar to the model Thisse and Vives (1988) have used to examine the choice of pricing regimes by horizontally differentiated duspolists. Like Thisse and Vives (1988) the paper finds that a transition from uniform to discriminatory pricing affects profits via two channels: An enhanced capacity to extract surplus from some buyers and an intensification of competition for the patronage of other buyers. $^{5}$ However, the results differ from Thisse and Vives (1988) in regard to the existence of a prisoners dilemma. When differentiation is horizontal both duopolists are better off by enforcing an agreement to price uniformly. When differentiation is vertical the Nash equilibrium in discriminatory price schedules is not always Pareto dominated by such agreement. The paper shows

\footnotetext{
${ }^{5}$ Ulph and Vulkan (2000) develop a similar model. They find that a switch from uniform pricing to discriminatory pricing boosts profits when transport cost increases rapidly with distance.
} 
that a prisoner's dilemma arises if and only if the ratio of market areas served by the two firms lies within a certain interval whose bounds can be calculated using generally observable data.

While the paper is formally close to Choudhary et al. (2005), it is different in spirit and addresses a wider set of issues. Specifically, it determines a pricing regime as an equilibrium strategy. Choudhary et al. (2005) focus on the comparison of prices and qualities under alternative exogenously given pricing regimes. Also, this paper assumes a more general distribution of consumer preferences, and a more general cost function. ${ }^{6}$

Section 2 introduces the model and section 3 characterizes the equilibrium that emerges from the simultaneous choice of discriminatory price schedules by the two firms. It establishes that personalized prices are not monotonic in consumers' willingness to pay. It shows why competition in discriminatory price schedules yields a welfare maximizing market coverage, and a welfare maximizing partition of the market into buyers of high and low quality. Section 4 takes up the question whether discrimination by the duopolists is an equilibrium strategy when the pricing regime is endogenous. Section 5 shows that in contrast to the case of horizontal differentiation, prior commitments by both firms to set uniform prices does not necessarily enhance firms' profits. It analyzes under what conditions it does. Section 6 endogenizes the choice of qualities and establishes that duopolists who engage in discriminatory pricing set qualities that maximize welfare. Section 7 provides concluding remarks and examines implications for competition policy.

\section{The model}

Consider a market in which two firms serve a continuum of consumers. The size of the market is normalized to one. Each firm produces a single variety of a vertically differentiated product. For convenience the varieties are called "high quality" and "low quality" and denoted $s_{H}$ and $s_{L}$, where $s_{H}>s_{L}>0$. The producers of these qualities are caleld the high $(H)$ and the low $(L)$ quality firms.

Consumers have preferences à la Mussa-Rosen (1978). Each consumer is identified by a taste parameter $\theta \in[0, b]$ distributed with positive and continuous density $f(\theta)$ over the interval $[0, b]$ • A consumer buys a single unit of high or low quality, or nothing at all. Consumer $\theta^{\prime} s$ reservation price

\footnotetext{
${ }^{6}$ The differences are examined in greater detail in the body of paper.
} 
for a single unit of quality $s_{i}$ is $\theta s_{i}(i \in\{H, L\})$. Consumer $\theta$ gets a surplus $\theta s_{i}-p_{i}(\theta)$ from a unit of quality $s_{i}$ purchased at the price $p_{i}(\theta)$, and a zero surplus from no purchase. Consumers cannot resell.

The cost of producing $q_{i}$ units of quality $s_{i}$ is $C\left(s_{i}, q_{i}\right)=c\left(s_{i}\right) q_{i}$ where $c\left(s_{i}\right)$ denotes the unit cost of quality $s_{i}$. The function $c($.$) is twice differentiable,$ strictly increasing, and strictly convex. Specifically :

$$
c(0)=0, c^{\prime}(s)>0, c^{\prime \prime}(s)>0, \forall s>0
$$

The latter implies:

$$
0<\frac{c\left(s_{L}\right)}{s_{L}}<\frac{c\left(s_{H}\right)}{s_{H}}<\frac{c\left(s_{H}\right)-c\left(s_{L}\right)}{s_{H}-s_{L}}, \forall s_{H}>s_{L}>0
$$

Because the paper focuses on producers' choices among pricing regimes, it assumes that both firms are active under all regimes being considered. Condition (3) below ensures this.

$$
b>\frac{c\left(s_{H}\right)-c\left(s_{L}\right)}{s_{H}-s_{L}}, \forall s_{H}>s_{L}>0(3)
$$

The term price schedule refers to a positive valued function $p_{i}($.$) defined$ on $[0, b]$ that specifies the price $p_{i}(\theta)$ at which firm $i$ is willing to sell one unit to consumer $\theta$. A price schedule is uniform when a single price targets all consumers. It is perfectly discriminating or personalized, when its component prices vary according to the taste parameters of each individual consumers that they target.

The paper examines four pricing regimes. Under the uniform regime, denoted $\left(U_{H}, U_{L}\right)$, both firms set uniform price schedules. Under the discriminatory regime, denoted $\left(D_{H}, D_{L}\right)$, both firms set discriminatory price schedules. The remaining regimes, denoted $\left(U_{H}, D_{L}\right)$ and $\left(D_{H}, U_{L}\right)$, are asymmetric. One firm sets a uniform price acting as a Stackelberg leader, while the other firm sets a perfectly discriminating schedule.

\section{Regime $\left(D_{H}, D_{L}\right)$}

For any pair of price schedules $\left(p_{H}(),. p_{L}().\right)$, the market areas served by firms $H$ and $L$ are :

$$
\Theta_{H}\left(p_{H}(.), p_{L}(.)\right)=\left\{\theta \in[0, b] / \theta s_{H}-p_{H}(\theta) \geq \operatorname{Max}\left[0, \theta s_{L}-p_{L}(\theta)\right]\right\}
$$




$$
\Theta_{L}\left(p_{H}(.), p_{L}(.)\right)=\left\{\theta \in[0, b] / \theta s_{L}-p_{L}(\theta) \geq \operatorname{Max}\left[0, \theta s_{H}-p_{H}(\theta)\right]\right\}
$$

Therefore, firm's $i$ profits $(i \in\{H, L\})$ are:

$$
\Pi_{i}\left(p_{H}(.), p_{L}(.)\right)=\int_{\Theta_{i}\left(p_{H}(.), p_{L}(.)\right)}\left[p_{i}(\theta)-c\left(s_{i}\right)\right] f(\theta) d \theta(6)
$$

Firm $i$ is said to have a monopoly position with respect to consumer $\theta$ if for any price schedule chosen by the rival $j$, it can attract that consumer with a price $\theta s_{i}$ that leaves zero surplus to the consumer. Firm $i$ is said to have a cost-quality advantage over it's rival $j$ with respect to consumer $\theta$ if there exists a price $p_{i}(\theta)$ at which it can attract consumer $\theta$ when the rival $j$ targets consumer $\theta$ with a price equal to its unit cost $c\left(s_{j}\right)$. Clearly, a firm that holds a monopoly position with respect to a consumer also holds a cost-quality advantage over its rival with respect to the same consumer. The converse is not true.

Proposition 1 characterizes the Nash equilibrium of the pricing game in which both firms independently choose the discriminatory regime.

Proposition 1 The Nash equilibrium of the game in discriminatory price schedules with payoffs given by (6) is the pair $\left(p_{H}^{*}(\theta), p_{L}^{*}(\theta)\right)$ defined by (7) and (8) below where $p_{H}(\theta)$ and $p_{L}(\theta)$ are any price schedules above unit costs.

$$
\begin{aligned}
& p_{H}^{*}(\theta)=\left\{\begin{array}{clc}
c\left(s_{L}\right)+\theta\left(s_{H}-s_{L}\right) & \text { if } & \frac{c\left(s_{H}\right)-c\left(s_{L}\right)}{s_{H}-s_{L}} \leq \theta \leq b \\
c\left(s_{H}\right) & \text { if } & \frac{c\left(s_{H}\right)}{s_{H}} \leq \theta<\frac{c\left(s_{H}\right)-c\left(s_{L}\right)}{s_{H}-s_{L}} \\
p_{H}(\theta) \geq c\left(s_{H}\right) & \text { if } & 0 \leq \theta<\frac{c\left(s_{H}\right)}{s_{H}}
\end{array}\right. \\
& p_{L}^{*}(\theta)=\left\{\begin{array}{clc}
c\left(s_{L}\right) & \text { if } & \frac{c\left(s_{H}\right)-c\left(s_{L}\right)}{s_{H}-s_{L}} \leq \theta \leq b \\
c\left(s_{H}\right)-\theta\left(s_{H}-s_{L}\right) & \text { if } & \frac{c\left(s_{H}\right)}{s_{H}} \leq \theta<\frac{c\left(s_{H}\right)-c\left(s_{L}\right)}{s_{H}-s_{L}} \\
\theta s_{L} & \text { if } & \frac{c\left(s_{L}\right)}{s_{L}} \leq \theta<\frac{c\left(s_{H}\right)}{s_{H}} \\
p_{L}(\theta) \geq c\left(s_{L}\right) & \text { if } & 0 \leq \theta<\frac{c\left(s_{L}\right)}{s_{L}}
\end{array}\right.
\end{aligned}
$$

Proof: 
Under perfect discrimination each consumer pays a price determined solely by that consumer's preference for quality. This follows immediately from the assumptions that reselling among consumers is impossible, and that unit cost is independent of quantity. No firm sells below unit cost to any consumer because doing so does not allow it to earn a larger profit from another consumer. Therefore, competition in discriminatory price schedules adds up to a collection of Bertrand games for individual consumers.

One can now examine the equilibrium in four market segments, using the simplified notation $c_{H}$ for $c\left(s_{H}\right)$ and $c_{L}$ for $c\left(s_{L}\right)$.

1. $\theta \in\left[\frac{c_{H}-c_{L}}{s_{H}-s_{L}}, b\right]$

When $p_{L}^{*}(\theta)=c_{L}$ consumers derive positive surplus from purchasing low quality. The highest price $p_{H}(\theta)$ at which they would purchase high quality satisfies the condition $\theta s_{H}-p_{H}(\theta)=\theta s_{L}-c_{L}$ which implies (7). When the $H$-firm sets $p_{H}^{*}(\theta)=c_{L}+\theta\left(s_{H}-s_{L}\right)$, consumers obtain a surplus $\theta s_{L}-c_{L}$ from high quality. They would purchase low quality only if it were priced below unit cost, which is non profitable. Therefore, $p_{L}^{*}(\theta)=c_{L}$ is an optimal response by firm $L$ to the schedule $p_{H}^{*}(\theta)$. Firm $H$ enjoys a cost-quality advantage over firm $L$, but no monopoly position, with respect to all consumers in the interval.

2. $\theta \in\left[\frac{c_{H}}{s_{H}}, \frac{c_{H}-c_{L}}{s_{H}-s_{L}}[\right.$

For $p_{L}^{*}(\theta)=c_{H}-\theta\left(s_{H}-s_{L}\right)$ consumers in the interval obtain a surplus $\theta s_{H}-c_{H}$ from low quality. Firm $H$ can attract these consumers only by pricing below unit cost. Because this yields a negative profit without producing a compensatory increase in profits from consumers in other intervals, a best response of firm $H$ is to set the price $c_{H}$. And, when $p_{H}^{*}(\theta)=c_{H}$, the highest price at which firm $L$ can attract consumers satisfies the condition $\theta s_{L}-p_{L}^{*}(\theta)=\theta s_{H}-c_{H}$ which implies (7). Clearly, firm $L$ has a cost-quality advantage but no monopoly position with respect to consumers in this interval.

3. $\theta \in\left[\frac{c_{L}}{s_{L}}, \frac{c_{H}}{s_{H}}[\right.$.

All price schedules above unit cost are optimal for firm $H$ because firm $L$ holds a monopoly position in the interval. The best response of firm $L$ is to set $p_{L}^{*}(\theta)=\theta s_{L}$ which allows its capture of the entire consumer surplus.

4. $\theta \in\left[0, \frac{c_{L}}{s_{L}}[\right.$

Within this interval no firm can attract a consumer by pricing at unit cost or higher. This is true for any price schedule chosen by the rival producer. All pairs of schedules with no component below unit cost ensure zero sales 
and are therefore equilibria. QED

Substitution of (7) and (8) into (6) yields the equilibrium profits:

$$
\begin{gathered}
\Pi_{H}\left(D_{H}, D_{L}\right)=\int_{\frac{c_{H}-c_{L}}{s_{H}-s_{L}}}^{b}\left[c_{L}+\theta\left(s_{H}-s_{L}\right)-c_{H}\right] f(\theta) d \theta(9) \\
\Pi_{L}\left(D_{H}, D_{L}\right)=\int_{\frac{c_{L}}{s_{L}}}^{\frac{c_{H}}{s_{H}}}\left[\theta s_{L}-c_{L}\right] f(\theta) d \theta+\int_{\frac{c_{H}}{s_{H}}}^{\frac{c_{H}-c_{L}}{s_{H}-s_{L}}}\left[c_{H}-\theta\left(s_{H}-s_{L}\right)-c_{L}\right] f(\theta) d \theta(10)
\end{gathered}
$$

Figure 1 displays the equilibrium. ${ }^{7}$ The lines labeled $\theta s_{H}$ and $\theta s_{L}$ represent the participation constraints for high and low quality buyers. The line segment $K M$ is the self-selection constraint faced by the high quality firm when its rival sells at unit cost. Similarly, the line segment $T L$ represents the self-selection constraint faced by the low quality firm when its rival offers high quality at unit cost. The high quality firm serves the market segment $\left[\frac{c_{H}-c_{L}}{s_{H}-s_{L}}, b\right]$ and sets the price schedule represented by $K M$. The low quality firm divides the consumers it serves into two segments. With respect to consumers with $\theta \in\left[\frac{c_{L}}{s_{L}}, \frac{c_{H}}{s_{H}}\right.$ [it sets prices at which the participation constraint is binding (VT in Figure 1). With respect to consumers with $\left.\theta \in] \frac{c_{H}}{s_{H}}, \frac{c_{H}-c_{L}}{s_{H}-s_{L}}\right]$ it sets prices at which the consumers' self-selection constraint binds ( $T L$ in Figure 1). Note that the price paid by these consumers decreases when their reservation price increases. This result is akin to the absorption effect in the Thisse and Vives (1988) model .

\section{INSERT FIGURE 1 HERE}

The profit earned by the high quality firm from an individual consumer is represented by the vertical distance between the line segment $K M$ and the horizontal line $c_{H}$. Because the total profit is a weighted sum of these distances on the segment $\left[\frac{c_{H}-c_{L}}{s_{H}-s_{L}}, b\right]$, we say that $\Pi_{H}\left(D_{H}, D_{L}\right)$ is area $(K M I)$, keeping in mind that the area is properly defined by the integral (9). Similarly, $\Pi_{L}\left(D_{H}, D_{L}\right)$ is area $(V T L)$.

\footnotetext{
${ }^{7}$ In the space $(\theta, p)$, the coordinates of points $T, L, V, K, M$ and $I$ are $\theta_{T}=\frac{c_{H}}{s_{H}}$, $p_{T}=c_{H} \frac{s_{L}}{s_{H}}, \theta_{L}=\frac{c_{H}-c_{L}}{s_{H}-s_{L}}, p_{L}=c_{L}, \theta_{V}=\frac{c_{L}}{s_{L}}, p_{V}=c_{L}, \theta_{K}=\frac{c_{H}-c_{L}}{s_{H}-s_{L}}, p_{K}=c_{H}, \theta_{M}=b$, $p_{M}=c_{L}+b\left(s_{H}-s_{L}\right)$ and $\theta_{I}=b, p_{I}=c_{H}$.
} 
Proposition 1 entails the following:

Corollary: Personalized prices competition by quality differentiated duopolists (regime $\left(D_{H}, D_{L}\right)$ ) yields a market coverage and a segmentation of consumers into high and low quality buyers that maximize total welfare.

Proof:

Each unit sold to yields a positive total surplus larger than the total surplus that would be have been generated from a sale to the same consumer of a unit of the other quality. This follows from the fact that a consumer who purchases low quality must gain less in utility from switching to high quality than would be added in to the cost production. Similarly, a consumer of high quality would lose more in utility from switching to low quality than the saving in production cost. QED

\section{Selecting a price policy.}

One can now address the question whether price discrimination is an equilibrium of a game in which firms can commit to price uniformly. Consider a three-stage game. In the first stage, each firm chooses whether to commit to a uniform schedule. If the two firms commit, they sell at the second stage at the prices they committed to. This is the regime $\left(U_{H}, U_{L}\right)$. If no firm commits in the first period, each remains free to set any price schedule in the second stage. This is the regime $\left(D_{H}, D_{L}\right)$. If one of the duopolists commits at the first stage, it acts as a Stackelberg leader at the second stage, while the other acts as a follower. These asymmetric regimes are denoted $\left(U_{H}, D_{L}\right)$ and $\left(D_{H}, U_{L}\right){ }^{8}$ In all regimes, consumers make their purchasing decisions at the last stage.

Committing to a uniform price can only be rational if it elicits a pricing response on the part of the rival that is favorable to the firm that makes the commitment. The credibility of such commitment may derive from sunk investments in a distribution channel that puts intermediaries between manufacturers and consumers and does not allow the former to ascertain individual consumer preferences. It can arise from a most-favored-customer clause granted by the seller. It may also rest on a threat of reputational losses

\footnotetext{
${ }^{8}$ We show in appendix 1 that there does not exist a Nash equilibrium in pure strategies within the framework of a static game where the high quality firm chooses a uniform price and the low quality firm chooses a perfectly discriminating price schedule. Thisse and Vives (1988) find the same for horizontal differentiation.
} 
that would ensue from backing down on the pre-announced uniform price. It is assumed that the firms committing to a uniform price take measures that lend credibility to their commitment. Howver these measures are not modeled.

\subsection{Regime $\left(U_{H}, D_{L}\right)$}

Suppose that the $H$-firm sets a uniform price $p_{H}>c_{H}$. The best response of the $L$-firm when is:

$$
p_{L}\left(\theta, p_{H}\right)=\left\{\begin{array}{clc}
c_{L} & \text { if } & \frac{p_{H}-c\left(s_{L}\right)}{s_{H}-s_{L}} \leq \theta \leq b \\
p_{H}-\theta\left(s_{H}-s_{L}\right) & \text { if } & \frac{p_{H}}{s_{H}} \leq \theta<\frac{c\left(s_{H}\right)-c\left(s_{L}\right)}{s_{H}-s_{L}} \\
\theta s_{L} & \text { if } & \frac{c\left(s_{L}\right)}{s_{L}} \leq \theta<\frac{p_{H}}{s_{H}} \\
p_{L}(\theta) \geq c\left(s_{L}\right) & \text { if } & 0 \leq \theta<\frac{c\left(s_{L}\right)}{s_{L}}
\end{array}\right.
$$

The profits are

$$
\begin{gathered}
\Pi_{L}\left(p_{H}, p_{L}(.)\right)=\int_{\frac{c_{L}}{s_{L}}}^{\frac{p_{H}}{s_{H}}}\left[\theta s_{L}-c_{L}\right] f(\theta) d \theta+\int_{\frac{p_{H}}{s_{H}}}^{\frac{p_{H}-c_{L}}{s_{H}-s_{L}}}\left[p_{H}-\theta\left(s_{H}-s_{L}\right)-c_{L}\right] f(\theta) d \theta \\
\Pi_{H}\left(p_{H}, p_{L}\left(., p_{H}\right)\right)=\int_{\frac{p_{H}-c_{L}}{s_{H}-s_{L}}}^{b}\left[p_{H}-c_{H}\right] f(\theta) d \theta(13)
\end{gathered}
$$

Because $\Pi_{H}$ is a continuous function of $p_{H}$, there exists a $p_{H}^{*}$ that maximizes $\Pi_{H}$ over the compact set $\left[c_{H}, b s_{H}\right]$. The Stackelberg equilibrium of the game where the $H$ and $L$-firms act respectively as a leader and a follower is the pair $\left(p_{H}^{*}, p_{L}\left(\theta, p_{H}^{*}\right)\right)$ where $p_{L}\left(\theta, p_{H}\right)$ is given by $(11)$.

Figure 2 displays the profits $\Pi_{L}\left(p_{H}, p_{L}().\right)$ as area $(V A B)$ and $\Pi_{H}\left(p_{H}, p_{L}\left(., p_{H}\right)\right)$ as $\operatorname{area}(F G I N)$. Because $\frac{c_{L}}{s_{L}}<\frac{c_{H}}{s_{H}}<\frac{c_{H}-c_{L}}{s_{H}-s_{L}}<\frac{p_{H}-c_{L}}{s_{H}-s_{L}}$, it must be true that $V T L \subset V A B$ or $\Pi_{L}\left(D_{H}, D_{L}\right)<\Pi_{L}\left(p_{H}, p_{L}().\right)$. For the same reason, $F G I N \subset K M I$ or $\Pi_{H}\left(p_{H}, p_{L}\left(., p_{H}\right)\right)<\Pi_{H}\left(D_{H}, D_{L}\right)$. One can therefore conclude that a high quality firm that commits to the uniform price $p_{H}^{*}>c_{H}$ while its rival does not commit, earns less than it would earn if no one committed. This is true despite the fact that commitment bestows upon the high quality firm a role of Stackelberg leader. 


\section{INSERT FIGURE 2 HERE}

Upon defining $p_{H}^{*}=\arg \max _{p_{H} \in\left[c_{H}, b s_{H}\right]} \Pi_{H}\left(p_{H}, p_{L}\left(., p_{H}\right)\right)$, one can write

$\Pi_{H}\left(U_{H}, D_{L}\right) \equiv \Pi_{H}\left(p_{H}^{*}, p_{L}\left(., p_{H}^{*}\right)\right)$ and $\Pi_{L}\left(U_{H}, D_{L}\right) \equiv \Pi_{L}\left(p_{H}^{*}, p_{L}\left(., p_{H}\right)\right)$

with $p_{L}\left(\theta, p_{H}^{*}\right)$ given by $(11)$. Because $\Pi_{H}\left(p_{H}, p_{L}\left(., p_{H}\right)\right)<\Pi_{H}\left(D_{H}, D_{L}\right)$ holds true for any $p_{H}>c_{H}$ it holds true for $p_{H}^{*}$ as well. Therefore:

$$
\Pi_{H}\left(U_{H}, D_{L}\right)<\Pi_{H}\left(D_{H}, D_{L}\right)
$$

and

$$
\Pi_{L}\left(U_{H}, D_{L}\right)>\Pi_{L}\left(D_{H}, D_{L}\right)
$$

Figure 2 clarifies the differences between the $\left(U_{H}, D_{L}\right)$ and $\left(D_{H}, D_{L}\right)$ regimes: i) Commitment by firm $H$ to a uniform price $p_{H}>c_{H}$ shifts the self-selection constraint faced by the low quality firm upward (from $T L$ to $A B)$ and shortens the self-selection constraint faced by the high quality firm (from $K M$ to $F M$ ); ii) the market coverage is the same under the two regimes although the market area served by the high quality firm is smaller under $\left(U_{H}, D_{L}\right)$ regime than under the $\left(D_{H}, D_{L}\right)$ regime, and the market served by the low quality firm is larger ${ }^{9}$; iii) the market area of the low quality buyers who retain no surplus is larger under the $\left(U_{H}, D_{L}\right)$ regime than under the $\left(D_{H}, D_{L}\right)$ regime.

\subsection{Regime $\left(D_{H}, U_{L}\right)$}

Assume that the $L$-firm sets a uniform price $p_{L}>c_{L}$. Clearly $p_{L} \geq c_{H}$ cannot be sustained as an equilibrium because the $H$-firm could undercut the $L$-firm, capture the market served by the $L$-firm, and increase its profit by doing so. When the low quality firm commits to a uniform price $p_{L} \in\left(c_{L}, c_{H}\right)$ the best response of the high quality producer depends on whether $\theta$ is larger or smaller than $\frac{c_{H}-p_{L}}{s_{H}-s_{L}}$. For $\theta<\frac{c_{H}-p_{L}}{s_{H}-s_{L}}$, any schedule $p_{H}(\theta) \geq c_{H}$ yields zero

\footnotetext{
${ }^{9}$ This comes about because the firm that commits has no interest in competing agressively for consumers who are more or less indifferent between the two qualities when each is priced at unit cost. The reason it does not is that it would have to accept a lower margin on sales to consumers with a strong preference for its quality.
} 
sales and is therefore a best response. Thus, the best response of firm $H$ to $p_{L} \in\left(c_{L}, c_{H}\right)$ is :

$$
p_{H}\left(\theta, p_{L}\right)=\left\{\begin{array}{clc}
p_{L}+\theta\left(s_{H}-s_{L}\right) & \text { for } & \theta \in\left[\frac{c_{H}-p_{L}}{s_{H}-s_{L}}, b\right] \\
p_{H}(\theta) \geq c_{H} & \text { for } & \theta<\frac{c_{H}-p_{L}}{s_{H}-s_{L}}
\end{array}\right.
$$

Profits are:

$$
\begin{array}{r}
\Pi_{H}\left(p_{H}\left(., p_{L}\right), p_{L}\right)=\int_{\frac{c_{H}-p_{L}}{s_{H}-s_{L}}}^{b}\left[p_{L}+\theta\left(s_{H}-s_{L}\right)-c_{H}\right] f(\theta) d \theta \\
\Pi_{L}\left(p_{H}\left(., p_{L}\right), p_{L}\right)=\int_{\frac{p_{L}}{s_{L}}}^{\frac{c_{H}-p_{L}}{s_{H}-s_{L}}}\left(p_{L}-c_{L}\right) f(\theta) d \theta(18)
\end{array}
$$

Note that the condition $\frac{p_{L}}{s_{L}}<\frac{c_{H}-p_{L}}{s_{H}-s_{L}}$ which ensures positive sales for the $L$-firm [see (18)] is equivalent to $\frac{s_{L}}{p_{L}}>\frac{s_{H}}{c_{H}}$. Using the same arguments as for regime $\left(D_{L}, U_{H}\right)$ one can show $\Pi_{H}\left(p_{H}\left(., p_{L}\right), p_{L}\right)>\Pi_{H}\left(D_{H}, D_{L}\right)$ and $\Pi_{L}\left(p_{H}\left(., p_{L}\right), p_{L}\right)<\Pi_{L}\left(D_{H}, D_{L}\right)$ which imply

$$
\Pi_{L}\left(D_{H}, U_{L}\right)<\Pi_{L}\left(D_{H}, D_{L}\right)(19)
$$

and

$$
\Pi_{H}\left(D_{H}, U_{L}\right)>\Pi_{H}\left(D_{H}, D_{L}\right)(20)
$$

One observes the following differences between the $\left(D_{H}, U_{L}\right)$ and the $\left(D_{H}, D_{L}\right)$ regimes: 1) Total market coverage is smaller under the $\left(D_{H}, U_{L}\right)$ regime; ii) the segment served by the low quality firm is smaller under the $\left(D_{H}, U_{L}\right)$ regime whereas the segment served by the high quality producer is larger.

\subsection{Regime $\left(U_{H}, U_{L}\right)$}

This is the standard regime examined in the literature. The concavity of $f(\theta)$ over $[0, b]$ is a sufficient condition for the existence of an equilibrium for an arbitrary distribution of consumer preferences. ${ }^{10}$ It is assumed that this condition is met.

Existence of a Nash equilibrium in uniform prices together with (14) and (19) imply the following proposition:

\footnotetext{
${ }^{10}$ See Bonnisseau and Lahmandi-Ayed (2005)
} 
Proposition 2 For any concave density function $f(\theta)$, personalization of prices is a subgame perfect equilibrium of the three-stage game where: if vertically differentiated duopolists determine whether or not to commit to a specific uniform price in a first stage; ii) in the second stage a firm that commited acts as a Stackelberg leader stage vis-a-vis a firm that did not commit, and if no one commited, both simultaneously set their price schedules; iii) in the third stage consumers make their purchases.

For a general density function one cannot compare the profits under this equilibrium with the profits generated under a mutual commitment to price uniformly. To compare profits under the two pricing regimes, the next section assumes a specific density function.

\section{$5 \quad$ A prisoner's dilemma?}

The finding that price personalization constitutes a subgame perfect equilibrium is the counterpart for quality differentiation of the Thisse and Vives (1998) result for horizontal differentiation. Thisse and Vives (1998) also established that spatially differentiated duopolists would be better off if they enforced an agreement to set uniform prices. This section shows for the particular case of a uniform distribution of consumer preferences - also studied by Thisse and Vives - that discrimination need not be Pareto dominated by uniform pricing when differentiation is vertical.

Table 1 displays the profits of the high and low quality firms for each of the four pricing regimes for uniform $f(.) .^{11}$

\footnotetext{
${ }^{11}$ Appendix 2 gives the details of the derivation of Table 1.
} 


\begin{tabular}{|c|c|c|}
\hline & $D_{L}$ & $U_{L}$ \\
\hline$D_{H}$ & $\Pi_{H}=\frac{s_{H}-s_{L}}{2 b}\left[b-\frac{c_{H}-c_{L}}{s_{H}-s_{L}}\right]^{2}$ & $\Pi_{H}=\frac{s_{H}-s_{L}}{2 b}\left[b-\frac{1}{2}\left(\frac{c_{H}-c_{L}}{s_{H}-s_{L}}+\frac{c_{H}}{s_{H}}\right)\right]^{2}$ \\
\hline$U_{H}$ & $\Pi_{L}=\frac{s_{L}}{2 b}\left[\frac{c_{H}-c_{L}}{s_{H}-s_{L}}-\frac{c_{L}}{s_{L}}\right]\left[\frac{c_{H}}{s_{H}}-\frac{c_{L}}{s_{L}}\right]$ & $\Pi_{L}=\frac{s_{L}}{4 b}\left[\frac{c_{H}}{s_{H}}-\frac{c_{L}}{s_{L}}\right]\left[\frac{c_{H}-c_{L}}{s_{H}-s_{L}}-\frac{c_{L}}{s_{L}}\right]$ \\
& $\Pi_{H}=\frac{s_{H}-s_{L}}{4 b}\left[b-\frac{c_{H}-c_{L}}{s_{H}-s_{L}}\right]^{2}$ & $\Pi_{H}=\frac{4 s_{H}^{2}\left(s_{H}-s_{L}\right)}{\left(4 s_{H}-s_{L}\right)^{2} b}\left[b-\frac{1}{2}\left(\frac{c_{H}-c_{L}}{s_{H}-s_{L}}+\frac{c_{H}}{s_{H}}\right)\right]^{2}$ \\
$\Pi_{L}=\frac{1}{2 b} \frac{s_{L}\left(s_{H}-s_{L}\right)}{s_{H}}\left[\frac{1}{2}\left(b+\frac{c_{H}-c_{L}}{s_{H}-s_{L}}\right)-\frac{c_{L}}{s_{L}}\right]^{2}$ & $\Pi_{L}=\frac{4 s_{L} s_{H}\left(s_{H}-s_{L}\right)}{\left(4 s_{H}-s_{L}\right)^{2} b}\left[\frac{1}{2}\left(b+\frac{c_{H}-c_{L}}{s_{H}-s_{L}}\right)-\frac{c_{L}}{s_{L}}\right]^{2}$ \\
\hline
\end{tabular}

Table 1: Profits under four pricing regimes with uniform density

One shows first that the Nash equilibrium $\left(D_{H}, D_{L}\right)$ is an equilibrium in dominant strategies. It has already been established that $\Pi_{H}\left(D_{H}, D_{L}\right)>$ $\Pi_{H}\left(U_{H}, D_{L}\right)$ and $\Pi_{L}\left(D_{H}, D_{L}\right)>\Pi_{L}\left(D_{H}, U_{L}\right)$ for any distribution $f(\theta)$. Table 1 now shows that for a uniform $f(\theta), \Pi_{H}\left(D_{H}, D_{L}\right)=2 \Pi_{H}\left(U_{H}, D_{L}\right)$ and $\Pi_{L}\left(D_{H}, D_{L}\right)=2 \Pi_{L}\left(D_{H}, U_{L}\right) .{ }^{12}$ Moreover, one easily checks that $0<s_{L}<$ $s_{H}$ entails $\frac{1}{4}<\frac{4 s_{H}^{2}}{\left(4 s_{H}-s_{L}\right)^{2}}<\frac{4}{9}$ implying $\Pi_{H}\left(D_{H}, U_{L}\right)>\Pi_{H}\left(U_{H}, U_{L}\right)$ and $\Pi_{L}\left(U_{H}, D_{L}\right)>\Pi_{L}\left(U_{H}, U_{L}\right)$. Therefore, $D_{H}$ and $D_{L}$ are dominant strategies for players $H$ and $L$.

Define now $\alpha \equiv s_{L} / s_{H}$, and $\lambda \equiv\left(b-\frac{c_{H}-c_{L}}{s_{H}-s_{L}}\right) /\left(\frac{c_{H}-c_{L}}{s_{H}-s_{L}}-\frac{c_{L}}{s_{L}}\right)$, i.e. $\lambda$ represents the ratio of market segments served by the two firms under the regime $\left(D_{H}, D_{L}\right)$. Consider the following intermediate result:

Lemma: There exist two functions $F_{H}(\alpha) \equiv \frac{\sqrt{2} \alpha}{4-2 \sqrt{2}-\alpha}$ and $F_{L}(\alpha) \equiv$ $\frac{4-2 \sqrt{2}-\alpha}{\sqrt{2}}$ such that $\Pi_{H}\left(D_{H}, D_{L}\right)>\Pi_{H}\left(U_{H}, U_{L}\right)$ if and only if $\lambda>F_{H}(\alpha)$ and $\Pi_{L}\left(D_{H}, D_{L}\right)>\Pi_{L}\left(U_{H}, U_{L}\right)$ if and only if $\lambda<F_{L}(\alpha)$.

Proof: See appendix 3.

The functions $F_{H}$ and $F_{L}$ which intersect for $\alpha=0.343$ partition the $(\alpha, \lambda)$ space into the four regions shown in Figure 3.

\section{Insert Figure 3}

\footnotetext{
${ }^{12}$ In this regard Choudhary et al.(2005) make a computational mistake in the calculation of $\Pi_{H}\left(U_{H}, D_{L}\right)$ which leads them to conclude that it is equal to $\Pi_{H}\left(D_{H}, D_{L}\right)$ [See their expressions (2) and (5)[.
} 
Partition of the $(\alpha, \lambda)$ space

In region 1 where $\alpha$ and $\lambda$ are such that $F_{H}(\alpha)<\lambda<F_{L}(\alpha)$, the $\left(D_{H}, D_{L}\right)$ regime Pareto-dominates the $\left(U_{H}, U_{L}\right)$ regime. In region 2 where $\lambda>\max \left[F_{H}(\alpha), F_{L}(\alpha)\right]$ firm $H$ is better off under the $\left(D_{H}, D_{L}\right)$ regime whereas firm $L$ prefers the $\left(U_{H}, U_{L}\right)$ regime. The opposite is true in region 3 where $\lambda<\min \left[F_{H}(\alpha), F_{L}(\alpha)\right]{ }^{13}$ It is only in region 4 where $F_{L}(\alpha)<$ $\lambda<F_{H}(\alpha)$ that the regime $\left(D_{H}, D_{L}\right)$ is Pareto dominated by the regime $\left(U_{H}, U_{L}\right)$. Thus:

Proposition 3 When consumer preferences are uniform over [0,b] and unit cost is a convex function of quality, the discriminatory pricing regime is Pareto dominated by the uniform regime if and only if the following conditions hold:

$$
\begin{aligned}
& \text { i) } \alpha \geq 0.343 \\
& \text { ii/ } b \in\left[F_{L}(\alpha)\left(\frac{c_{H}-c_{L}}{s_{H}-s_{L}}-\frac{c_{L}}{s_{L}}\right)+\frac{c_{H}-c_{L}}{s_{H}-s_{L}}, F_{H}(\alpha)\left(\frac{c_{H}-c_{L}}{s_{H}-s_{L}}-\frac{c_{L}}{s_{L}}\right)+\frac{c_{H}-c_{L}}{s_{H}-s_{L}}\right]
\end{aligned}
$$

While discrimination allows the extraction of more surplus from a first group of buyers, uniform pricing offers the advantage of less intense competition for the patronage of a second group of buyers. In the first group one finds the consumers who have a strong preference for a particular quality when the two qualities are offered at unit cost. The second group is made up of consumers with a weak preference for a particular quality when the two qualities are offered at unit cost. A necessary condition for both firms to be better off under discriminatory pricing is that each gains from the capacity to extract surplus from the first group a benefit that exceeds the harm it suffers as result of more intense competition for the second group. Discrimination can yield a higher profit only if there is a sufficient disparity in qualities, or equivalently if the ratio $\alpha=s_{L} / s_{H}$ is sufficiently small. $(\alpha<0.343)$. Indeed, when the latter condition is not met, there are no consumers with a strong preference for a particular quality. However, this condition is not sufficient. No firm prefers discrimination if the number of its "captive" buyers is not sufficiently large in relation to the number of its "non-captive" buyers. This explains why discrimination is Pareto-dominated only if the ratio of market areas - the ratio of "captive" to "non-captive" buyers - takes on intermediate

\footnotetext{
${ }^{13}$ It is straigthforward to show that for $c(s)=s^{2}$ a prisoner's dilemma occurs for $b \in$ ]2.45, 2.55[ when $s_{H}=1, s_{L}=0.5$ and for $\left.b \in\right] 1.63,1.9\left[\right.$ when $s_{H}=1, s_{L}=0.25$.
} 
values $\left(F_{H}(\alpha)<\lambda<F_{L}(\alpha)\right)$. Conversely, discriminatory price schedules are dominant when both firms have captive consumers in numbers sufficiently large relative to "non-captive" buyers.

Because market shares and qualities are generally observable, one can determine if the conditions of the last proposition are satisfied, on the basis of information about the reservation price of consumers with the highest willingness to pay.

The proposition carries an implication for competition policy: When the conditions stated in the proposition are met, it is unlikely that a sudden switch by duopolists from discriminatory pricing to uniform pricing - perhaps via adoption of a most-favored customer clause - is brought about by independent action.

It is useful at this stage to set the results against Choudhary et al. (2005). These authors focus on the question how price and quality choices vary across pricing regimes. They do so numerically for a more restricted class of cost functions. The game, as Choudhary et al. describe it, unfolds as follows: At stage 1, firms simultaneously choose qualities, at stage 2 they select prices, and at stage 3 consumers decide which product, if any they purchase. Choudhary et al. (2005) start with the determination of equilibrium qualities for each of four exogenously given pricing regimes and then they compare profits across regimes taking into account of the fact that qualities as well as prices vary from one regime to the other. They fail to account for the fact that unless firms make a credible commitment to a particular pricing regime before setting qualities at stage 1 , it is optimal for each of them to choose a discriminatory schedule at stage 2 . This is true regardless of the qualities selected. For that reason, their equilibria do not conform to the description of their game and their comparison of profits does not shed light on the circumstances that give rise to a prisoner's dilemma.

This paper by contrast focuses on the question whether firms have an incentive to agree to price uniformly for a given pair of qualities. This is certainly appropriate when qualities are given exogeneously. It is also appropriate when all decisions in regard to pricing follow the selection of qualities and are not constrained by the quality choices. The latter assumption appears more reasonable from an empirical perspective. ${ }^{14}$

\footnotetext{
${ }^{14} \mathrm{We}$ are hesitant to compare our results with Choudhary et al. (2005) because of a computational error in their paper. They find that the profit of the $H$ - firm in the particular case where only the $L$ - firm discriminates is equal to the profit of the $H$-firm when both firms discriminate. As Table 1 shows the profit of the $H$-firm under the
} 
The following corollary compares the aggregate consumer surplus under regimes $\left(D_{H}, D_{L}\right)$ and $\left(U_{H}, U_{L}\right)$.

Corollary: When the conditions ensuring the existence of a prisonner's dilemma are met, aggregate consumer surplus is higher when firms engage in personalized pricing than when they price uniformly.

Proof: The proof follows from the definition of aggregate welfare and from the result that aggregate welfare is maximized when the two firms choose profit-maximizing discriminatory price schedules.

\section{Quality choice by discriminating duopolists.}

Until now qualities were given. This section characterizes the equilibrium when qualities are endogenous. It does so for any density function $f(\theta)$ and convex unit cost function $c(s)$. Do examine quality choices one must add an initial stage to the game. At this initial stage both firms choose their qualities independently within a bounded interval $[0, S]$ where the upper value $S$ is the highest quality allowed by technology. The subsequent stages are identical to the pricing game studied in the earlier sections. Because it has already been established that the subgame perfect equilibrium pricing strategy is discrimination by both firms regardless of quality, it is sufficient to consider this regime.

For all $s_{H}>s_{L}>0$, the Nash equilibrium in qualities satisfies the first order conditions (21) and (22) below, obtained from differentiation of (9) and (10) with respect to $s_{H}$ and $s_{L} \cdot{ }^{15}$

$$
\begin{aligned}
& \int_{\frac{c\left(s_{H}\right)-c\left(s_{L}\right)}{s_{H}-s_{L}}}^{b}\left[\theta-c^{\prime}\left(s_{H}\right)\right] f(\theta) d \theta=0(21) \\
& \int_{\frac{c\left(s_{L}\right)}{s_{L}}}^{\frac{c\left(s_{H}\right)-c\left(s_{L}\right)}{s_{H}-s_{L}}}\left[\theta-c^{\prime}\left(s_{L}\right)\right] f(\theta) d \theta=0(22)
\end{aligned}
$$

Conditions (21) and (22) simply state that the marginal cost of each

$\left(U_{H}, D_{L}\right)$ regime is only half as large as under the $\left(D_{H}, D_{L}\right)$ regime when the distribution of consumer preferences is uniform.

${ }^{15}$ Convexity of the unit cost function implies that the second order conditions are satisfied. 
quality equals the average marginal utility of buyers of that quality. ${ }^{16}$

The following proposition characterizes the subgame-perfect equilibrium in qualities

Proposition 4 For any density function of consumer preferences and convex unit cost of quality, the sub-game perfect equilibrium qualities are socially optimal.

Proof: Total welfare is

$W\left(s_{H}, s_{L}\right)=\int_{\frac{c\left(s_{L}\right)}{s_{L}}}^{\frac{c\left(s_{H}\right)-c\left(s_{L}\right)}{s_{H}-s_{L}}}\left(\theta s_{L}-c\left(s_{L}\right)\right) f(\theta) d \theta+\int_{\frac{c\left(s_{H}\right)-c\left(s_{L}\right)}{s_{H}-s_{L}}}^{b}\left(\theta s_{H}-c\left(s_{H}\right)\right) f(\theta) d \theta$

Differentiation of (23) with respect to $s_{L}$ yields

$$
\begin{aligned}
& \frac{\partial W\left(s_{H}, s_{L}\right)}{\partial s_{L}}=\int_{\frac{c_{L}}{s_{L}}}^{\frac{c_{H}-c_{L}}{s_{H}-s_{L}}}\left[\theta-c^{\prime}\left(s_{L}\right)\right] f(\theta) d \theta \\
& +\left[\frac{c\left(s_{H}\right)-c\left(s_{L}\right)}{s_{H}-s_{L}} s_{L}-c\left(s_{L}\right)\right] f\left(\frac{c\left(s_{H}\right)-c\left(s_{L}\right)}{s_{H}-s_{L}}\right) \frac{\partial\left[\frac{c\left(s_{H}\right)-c\left(s_{L}\right)}{s_{H}-s_{L}}\right]}{\partial s_{L}} \\
& -\left[\frac{c\left(s_{L}\right)}{s_{L}} s_{L}-c\left(s_{L}\right)\right] f\left(\frac{c\left(s_{L}\right)}{s_{L}}\right) \frac{\partial\left[\frac{c\left(s_{L}\right)}{s_{L}}\right]}{\partial s_{L}} \\
& -\left[\frac{c\left(s_{H}\right)-c\left(s_{L}\right)}{s_{H}-s_{L}} s_{H}-c\left(s_{H}\right)\right] f\left(\frac{c\left(s_{H}\right)-c\left(s_{L}\right)}{s_{H}-s_{L}}\right) \frac{\partial\left[\frac{c\left(s_{H}\right)-c\left(s_{L}\right)}{s_{H}-s_{L}}\right]}{\partial s_{L}}=0
\end{aligned}
$$

One easily checks that the sum of the second and fourth terms of (24) is zero. The reason is that a switch between high and low quality changes the utility of the consumer $\theta=\frac{c_{H}-c_{L}}{s_{H}-s_{L}}$ by an amount equal to the difference in cost of the two qualities. Also, the third term of (24) is zero because for the consumer $\theta=\frac{c_{L}}{s_{L}}$ a change in quality changes utility by an amount equal to the production cost. Thus, (24) simplifies to (22).

\footnotetext{
${ }^{16}$ In order to conclude that conditions (21) and (22) define a Nash equilibrium in qualities, one must also establish that the firm producing the low quality has no incentive to deviate from $s_{L}^{*}$ [given by (22)] and set quality higher than $s_{H}^{*}$. But this raises the usual undeterminate question related to the identity of the firms, namely which one chooses the high quality given that the other one chooses the low quality.
} 
Similarly differentiation of (23) with respect to $s_{H}$, yields

$$
\begin{aligned}
& {\left[\frac{c\left(s_{H}\right)-c\left(s_{L}\right)}{s_{H}-s_{L}} s_{L}-c\left(s_{L}\right)\right] f\left(\frac{c\left(s_{H}\right)-c\left(s_{L}\right)}{s_{H}-s_{L}}\right) \frac{\partial\left[\frac{c\left(s_{H}\right)-c\left(s_{L}\right)}{s_{H}-s_{L}}\right]}{\partial s_{H}}} \\
& +\int_{\frac{c\left(s_{L}\right)}{s_{L}}}^{\frac{c\left(s_{H}\right)-c\left(s_{L}\right)}{s_{H}-s_{L}}}\left[\theta-c^{\prime}\left(s_{H}\right)\right] f(\theta) d(\theta) \\
& -\left[\frac{c\left(s_{H}\right)-c\left(s_{L}\right)}{s_{H}-s_{L}} s_{H}-c\left(s_{H}\right)\right] f\left(\frac{c\left(s_{H}\right)-c\left(s_{L}\right)}{s_{H}-s_{L}}\right) \frac{\partial\left[\frac{c\left(s_{H}\right)-c\left(s_{L}\right)}{s_{H}-s_{L}}\right]}{\partial s_{H}}=0
\end{aligned}
$$

which simplifies to (21) because the first and third terms cancel out. QED

The reason why the firms choose welfare maximizing qualities is obvious. Discrimination allows then to capture all the extra utility generated by an extra unit of quality. This guarantees that the equilibrium qualities are welfare maximizing when the cost of quality is convex.

\section{$7 \quad$ Final Remarks}

Perfect price discrimination is a Nash equilibrium of a game where quality differentiated duopolists determine first whether to commit to a uniform price and subsequently set prices and sell output. Whether specific consumers are better off under discrimination than under uniform pricing depends on the extent to which they are captive to one of the sellers. Discrimination benefits the consumers whose preference for one of the qualities is weak if both qualities are priced at unit cost. With respect to these consumers, the competition effect of discrimination outweighs the enhanced surplus extraction effect. Consumers who have a strong preference for one of the qualities when both are priced at unit cost, are worse off under discrimination.

In contrast to earlier contributions that focused on horizontal differentiation, this paper finds that under vertical differentiation both duopolists are not necessarily better off when they enforce an agreement to price uniformly. Necessary and sufficient conditions for both firms to earn higher profits under first-degree-discrimination are a sufficiently large disparity in qualities, and a spread of consumer preferences for quality that is neither too large nor too small. The paper also established that a unilateral move from uniform pricing to personalized pricing lowers the rival firm's profits. When consumer 
preferences are distributed uniformly and both firms engage in price discrimination, a unilateral deviation toward uniform pricing halves the deviating firm's profit.

The industrial organization literature shows that the grant of a mostfavored customer clause by a single duopolist increases the profits of all market participants by softening price competition. This paper shows that uniform pricing is critical to this outcome. In the absence of a commitment to uniform pricing, a unilateral grant of price protection to one's customers is always harmful to the party making the grant. More generally, the paper provides an easily verifiable condition that can be used to formulate aa presumption about the anticompetitive intent of a most-favored-customer clause.

The paper also shows that for any exogenously given quality pair, competition in discriminatory prices schedules yields a welfare maximizing coverage of the market, and a welfare maximizing segmentation into buyers of high and low quality. Furthermore, the qualities chosen by discriminating firms are welfare maximizing.

The paper has assumed that sellers have full information about consumers. It disregarded the possibility of manipulation of the information by consumers. It is clear that in practice much of the information is obtained by analyzing surfing patterns and purchasing history..This raises the question how the choice of pricing regimes is affected when buyers account for the effect of current purchases on future price offers. ${ }^{17}$ Nevertheless, it remains useful to model discrimination in the absence of strategic behavior because only a minority of consumers is aware that information collected about their purchasing behavior is shared, and may be used to price discriminate. ${ }^{18}$,

A policy implication of the paper is that imposing a minimum quality requirement lowers aggregate welfare in presence of discriminatory pricing. This contrasts with earlier results which show that a mildly restrictive quality standard raises welfare (Ronnen, 1991, Crampes and Hollander, 1995). Under uniform pricing, a minimum quality requirement increases market coverage as it narrows the quality gap and intensifies price competition. Such intensification also takes place when the firms engage in price discrimination. The reason, however, is different. The narrower quality gap intensifies price

\footnotetext{
${ }^{17}$ Some recent theoretical work (Acquisti and Varian (2003) and Villas-Boas (2003)) explores this question for the case of a monopolistic seller.

${ }^{18}$ Because the skills required to behave strategically are not widespread, one may assume that the percentage of buyers who behave strategically is even lower.[Turow et al. (2005)]
} 
competition by expanding the range of non-captive consumers. Furthermore a minimum quality requirement restricts market coverage when pricing is discriminatory. More importantly, the paper suggest that a reduction of the quality range - possibly in response to a minimum quality standard - may encourage firms to choose distribution channels or opt for contractual arrangements that ensure uniform prices. When this happens, there is a further reduction of market coverage, and a suboptimal segmentation of consumers into high and low quality buyers.

The industrial organization literature has devoted much attention to the question how market structure affects price levels. This paper enlarges the perspective by suggesting a new way through which market structure may affect the choice of a pricing regime. Entry for example, affects incentives to agree on unifom pricing when it reduces the disparity in qualities. This adds a new twist to the welfare effects of entry.

The standard reply to the question what differentiates an incumbent from an entrant is that the former can credibly commit to a course of action before the second firm appears on stage. The paper suggests that a greater capacity to engage in differential pricing may be an important distinguishing characteristic between the incumbent and the entrant. A pre-entry adoption of discriminatory pricing by the incumbent reveals information about buyers' reservation prices that the entrant cannot posses. The entrant is more likely - at least initially - to set a uniform price, or divide consumers into fewer classes for pricing purposes than the incumbent. The paper has shown that a firm that prices uniformly earns lower profits when its rival discriminates that when he prices uniformly. This suggests than an incumbent who discriminates prior to entry is more likely to deter entry than an incumbent who prices uniformly. ${ }^{19}$ For that reason, a threat of entry may encourage an incumbent to incur the sunk cost of acquiring information about consumer preferences.

The assumption that firms posses full information about individual reservation prices and that this information is acquired at no cost, obviously lacks realism (Varian, 2003). Information about consumer preferences is obtained from the analysis of data garnered in part from costly experimentation (Caminal and Matutes, 1990, Shaffer and Zhang, 2000). The cost of dividing con-

\footnotetext{
${ }^{19}$ See in this regard Aguirre et al., 1998.There is clearly no reason for the incumbent to move to uniform pricing post entry because discriminatory pricing gives the incumbent higher profits regardless of the price policy adopted by the entrant
} 
sumers into different classes increases with the number of classes. For that reason the problem in practice is not how to choose between perfect price discrimination and uniform pricing. It is to determine the optimal number of consumer classes considering that the cost of experimentation rises when consumers are partitionned in ever finer classes. One may well find that the equilibrium number of consumer classes depends on the disparity of qualities. Exactly how will have to await further research.

\section{References}

Acquisti, Alessandro and Hal. R. Varian, Conditioning prices on Purchases history, Marketing Science,2001, 24(3), pp. 367-381

Aguirre, Inaki., Maria Paz Espinossa and Ines Macho-Stadler, Strategic entry deterrence through spatial price discrimination, Regional Science and Urban Economics, 1998, 28, 297-314.

Bhaskar, V. and Ted To, Is perfect price discrimination really efficient? An analysis of free entry, The Rand Journal of Economics, 2004, 35 (4), 762-776.

Bonnisseau, Jean-Marc and Rim Lahmandi-Ayed, Vertical differentiation with non-uniform consumers' distribution, 2005,CERMSEM, mimeo

Caminal, Ramon. and Carmen. Matutes, Endogenous switching costs in duopoly models, International Journal of Industrial Organization, 1990, 8, 353-373.

Choudhary, Vidyanand, Anindya Ghose, Tridas Mukhopadhyay and Uday Rajan, Personalized pricing and quality differentiation, Management Science, 2005, 51, 7, 1120-1130.

Crampes Claude and Abraham Hollander, Duopoly and quality standards, European Economic Review, 1995, 39, 71-82.

Edlin Aaron S. and Daniel L. Rubinfeld, Exclusion or efficient pricing? The "big deal" bundling of academic journals", Antitrust Law Journal, 2004, vol.72, 119-157.

Emch, Eric.R., Price discrimination via proprietary aftermarkets, The B.E. Journals in Economic Analysis and Policy, Contributions to Economic Analysis \& Policy, 2003, 2, 1, www.bepress.com/bejeap/contributions/vol2/issue1/art4

Fudenberg, Drew. and Jean Tirole, Customer poaching and brand switching, The Rand Journal of Economics, 2000, 31(4), 634-657.

Hamilton, Jonathan $\mathrm{H}$ and Jean-François Thisse, Duopoly with spatial and quantity-dependent price discrimination, Regional Science and Urban Economics, 1992, 22, 175- 185. 
Hurter, Arthur and Phillip. Lederer, Spatial duopoly with discriminatory pricing, Regional Science and Urban Economics, 1985,15, 541-553.

Lederer Phillip and Arthur Hurter (1986), Competition of firms: Discriminatory pricing and location, Econometrica, 54, 623-640

Mussa, Michael. and Sherwin Rosen, Monopoly and product quality, Journal of Economic Theory, 1978, 18, 301-317.

Pigou, Arthur.C., The Economics of Welfare, 1920, Macmillan, 4th edition, London.

Ronnen Uri, Minimum quality standard, fixed costs and competition, The Rand Journal of Economics, 1991, 22 (4), 490-504.

Shaffer, Greg. and John Zhang, Pay to stay: preference based price discrimination in markets with switching costs, Journal of Economics and Management Strategy, 2000, 9 (3), 397-424.

Shapiro, Carl. and Hal. Varian, Information Rules, 1999, Harvard Business School Press, Boston, MA.

Stole, Lars.A., Price discrimination and imperfect competition, The Handbook of Industrial Organization, vol 3, forthcoming

Thisse, Jean.-François and Xavier Vives, On the strategic choice of spatial price policy, American Economic Review, 1988,vol.78, 1, 122-137.

Turow, Joseph, Lauren Feldman and Kimberley Meltzer, Open to exploitation: American shoppers online and offline, 2005, A report from the Annenberg Public Policy Center of the University of Pennsyvania, 32 pages

Ulph David. and Nir Vulkan, Electronic commerce and competitive firstdegree price discrimination, 2000, Working Paper, ESRC, University College London.

Ulph David. and Nir Vulkan, E-Commerce, mass customisation and price discrimination, 2001, Working Paper, ESRC, University College London.

Varian, Hal.R, Economics of information technology, 2003, University of California, Berkeley.

Villas-Boas, Miguel.J., Dynamic competition with customer recognition, The Rand Journal of Economics,1999, 30, 604-631 
Appendix 1: Non-existence of an equilibrium when simultaneously the $H$-firm chooses a uniform price and the $L$-firm chooses a personalized price scheme.

Proposition 5 The one-stage game where the high quality firm sets a uniform price and the low quality firm personalizes prices does not have an equilibrium in pure strategies.

Proof: We restrict the proof to the case of a uniform density where $f(\theta)=\frac{1}{b}$ for all $\theta \in[0, b]$. We already know that for a uniform price $p_{H} \geq c_{H}$, a best response of the low quality firm is given by:

$$
p_{L}\left(\theta, p_{H}\right)=\left\{\begin{array}{ccc}
\theta s_{L} & \text { for } & \frac{c_{L}}{s_{L}} \leq \theta \leq \frac{p_{H}}{s_{H}} \\
p_{H}-\theta\left(s_{H}-s_{L}\right) & \text { for } & \frac{p_{H}}{s_{H}}<\theta \leq \frac{p_{H}-c_{L}}{s_{H}-s_{L}} \\
c_{L} & \text { for } & \frac{p_{H}-c_{L}}{s_{H}-s_{L}}<\theta \leq b
\end{array}\right.
$$

The profit of the high quality firm is therefore

$$
\Pi_{H}\left(p_{H}, p_{L}\left(., p_{H}\right)\right)=\frac{1}{b}\left(p_{H}-c_{H}\right)\left(b-\frac{p_{H}-c_{L}}{s_{H}-s_{L}}\right)
$$

We show first that a pair $\left[p_{H}, p_{L}\left(\theta, p_{H}\right)\right]$ where $p_{H}>c_{H}$ cannot be an equilibrium. Take $p_{H}>c_{H}$ and consider a deviation by firm $H$ lowering its price to $\widetilde{p}_{H}=p_{H}-\epsilon$ where $0<\epsilon<p_{H}-c_{H}$. Consumers with $\left.\left.\theta \in\right] \frac{p_{H}}{s_{H}}, \frac{p_{H}-c_{L}}{s_{H}-s_{L}}\right]$ switch to the high quality because $\theta s_{H}-p_{H}+\epsilon>\theta s_{L}-p_{H}+\theta\left(s_{H}-s_{L}\right)$. Post deviation, the profit of the high quality firm is $\widetilde{\Pi}_{H}=\frac{1}{b}\left(\widetilde{p}_{H}-c_{H}\right)\left(b-\frac{\widetilde{p}_{H}}{s_{H}}\right)$. Therefore, $\widetilde{\Pi}_{H}-\Pi_{H}=\frac{1}{b}\left[-\epsilon\left(b-\frac{\widetilde{p}_{H}}{s_{H}}\right)+\left(p_{H}-c_{H}\right)\left(\frac{p_{H}-c_{L}}{s_{H}-s_{L}}-\frac{\widetilde{p}_{H}}{s_{H}}\right)\right]$. Because the second term on the right-hand-side can be made larger in absolute value than the first term, the deviation increases the profits of the high quality firm. This proves that there cannot be an equilibrium in pure strategies where $p_{H}>c_{H}$.

Consider now the case $p_{H}=c_{H}$ which entails $\Pi_{H}=0$. The best response of firm $L$ is to sell to consumers $\theta \in\left[\frac{c_{H}-c_{L}}{s_{H}-s_{L}}, b\right]$ at unit cost $c_{L}$. If firm $H$ deviates by choosing $\bar{p}_{H}=c_{H}+\frac{1}{2}\left[b\left(s_{H}-s_{L}\right)-\left(c_{H}-c_{L}\right)\right]>c_{H}$, the consumer $\bar{\theta}$ who is indifferent between high quality sold at $\bar{p}_{H}$ and low quality sold at unit cost must is defined by $\bar{\theta}=\frac{\bar{p}_{H}-c_{L}}{s_{H}-s_{L}}=\frac{1}{2}\left[b+\frac{c_{H}-c_{L}}{s_{H}-s_{L}}\right]$. Post deviation, the $H$ firm earns $\bar{\Pi}_{H}=\frac{1}{b}\left(\bar{p}_{H}-c_{H}\right)(b-\bar{\theta})>0$. This completes the proof.

Appendix 2: Derivation of Table 1 


\subsubsection{Regime $\left(U_{H}, D_{L}\right)$}

The best response of the $L$-firm to a commitment by the $H$-firm is given by (11) in the text. $\Pi_{H}\left(U_{H}, D_{L}\right)=\frac{1}{b}\left[p_{H}-c_{H}\right]\left[b-\frac{p_{H}-c_{L}}{s_{H}-s_{L}}\right]$ attains a maximimum for $p_{H}^{U_{H}, D_{L}}=\frac{1}{2}\left[c_{H}+c_{L}+b\left(s_{H}-s_{L}\right)\right]$ implying $\Pi_{H}\left(U_{H}, D_{L}\right)=$ $\frac{1}{2 b}\left[c_{L}-c_{H}+b\left(s_{H}-s_{L}\right)\right]\left[b-\frac{1}{2}\left(\frac{c_{H}-c_{L}}{s_{H}-s_{L}}+b\right)\right]$

$=\frac{s_{H}-s_{L}}{4 b}\left[b-\frac{c_{H}-c_{L}}{s_{H}-s_{L}}\right]^{2}$.Note that $b>\frac{c_{H}-c_{L}}{s_{H}-s_{L}}$ entails $p_{H}^{U_{H}, D_{L}}>c_{H}$. Ans, substitution of $p_{H}^{U_{H}, D_{L}}$ into (11) yields

$$
p_{L}^{U_{H}, D_{L}}(\theta)=\left\{\begin{array}{ccc}
c_{L} & \text { for } & \theta \geq \frac{1}{2}\left[\frac{c_{H}-c_{L}}{s_{H}-s_{L}}+b\right] \\
\frac{c_{H}+c_{L}+(b-2 \theta)\left(s_{H}-s_{L}\right)}{2} & \text { for } & \frac{1}{2} \frac{c_{H}+c_{L}+b\left(s_{H}-s_{L}\right)}{s_{H}}<\theta<\frac{1}{2}\left[\frac{c_{H}-c_{L}}{s_{H}-s_{L}}+b\right] \\
\theta s_{L} & \text { for } & \frac{c_{L}}{s_{L}} \leq \theta \leq \frac{1}{2} \frac{c_{H}+c_{L}+b\left(s_{H}-s_{L}\right)}{s_{H}}
\end{array}\right.
$$

The quantity sold by the $L$-firm is $\frac{1}{b}\left(\frac{1}{2}\left[\frac{c_{H}-c_{L}}{s_{H}-s_{L}}+b\right]-\frac{c_{L}}{s_{L}}\right)$. The low quality buyer who pays the highest price has preference index $\theta=\frac{1}{2} \frac{c_{H}+c_{L}+b\left(s_{H}-s_{L}\right)}{s_{H}}$ and pays the amount $\frac{c_{H}+c_{L}+b\left(s_{H}-s_{L}\right)}{2}-\frac{c_{H}+c_{L}+b\left(s_{H}-s_{L}\right)}{2 s_{H}}\left(s_{H}-s_{L}\right)=\frac{c_{H}+c_{L}+b\left(s_{H}-s_{L}\right)}{2} \frac{s_{l}}{s_{H}}$.

The profit earned from that consumer is $\left(\frac{c_{H}-c_{L}+2 c_{L}+b\left(s_{H}-s_{L}\right)}{2 s_{H}}\right) s_{L}-c_{L}=$ $\frac{\left(s_{H}-s_{L}\right)}{2} \frac{s_{L}}{s_{H}}\left(b+\frac{c_{H}-c_{L}}{s_{H}-s_{L}}\right)+\frac{s_{L}}{s_{H}} c_{L}-c_{L}$
$\quad=\frac{\left(s_{H}-s_{L}\right)}{2} \frac{s_{L}}{s_{H}}\left(b+\frac{c_{H}-c_{L}}{s_{H}-s_{L}}\right)-\frac{\left(s_{H}-s_{L}\right)}{s_{H}} c_{L}=\frac{s_{L}\left(s_{H}-s_{L}\right)}{s_{H}}\left[\frac{1}{2}\left(b+\frac{c_{H}-c_{L}}{s_{H}-s_{L}}\right)-\frac{c_{L}}{s_{L}}\right]$.

Because the distribution of $\theta^{\prime} s$ is uniform, the average profit per unit sold by the $L$-firm is half that amount. Therefore $\Pi_{L}=\frac{1}{2 b} \frac{s_{L}\left(s_{H}-s_{L}\right)}{s_{H}}\left[\frac{1}{2}\left(b+\frac{c_{H}-c_{L}}{s_{H}-s_{L}}\right)-\right.$ $\left.\frac{c_{L}}{s_{L}}\right]^{2}$.

\subsubsection{Regime $\left(D_{H}, U_{L}\right)$}

When the $L$-firm commits to a uniform price $\left.p_{L} \in\right] c_{L}, c_{H}[$, the $H$-firm responds by choosing (16). The profit of the $L$-firm is $\Pi_{L}\left(D_{H}, U_{L}\right)=\frac{1}{b}\left[p_{L}-\right.$ $\left.c_{L}\right]\left[\frac{c_{H}-p_{L}}{s_{H}-s_{L}}-\frac{p_{L}}{s_{L}}\right]$. It attains a maximum for $p_{L}^{D_{H}, U_{L}}=\frac{1}{2}\left[c_{L}+\frac{s_{L}}{s_{H}} c_{H}\right]=\frac{s_{L}}{2}\left[\frac{c_{H}}{s_{H}}+\frac{c_{L}}{s_{L}}\right]$ implying

$$
p_{L}^{D_{H}, U_{L}}-c_{L}=\frac{s_{L}}{2}\left[\frac{c_{H}}{s_{H}}-\frac{c_{L}}{s_{L}}\right] \text {. Also, } \frac{c_{H}-p_{L}}{s_{H}-s_{L}}=\frac{2 c_{H}-c_{L}-\frac{s_{L}}{s_{H}} c_{H}}{s_{H}-s_{L}}=\frac{1}{2}\left(\frac{c_{H}-c_{L}}{s_{H}-s_{L}}+\frac{c_{H}}{s_{H}}\right),
$$
and $\frac{p_{L}^{D_{H}, U_{L}}}{s_{L}}=\frac{1}{2}\left(\frac{c_{L}}{s_{L}}+\frac{c_{H}}{s_{H}}\right)$. Because $s_{L}<s_{H}$, is must be true that $p_{L}^{D_{H}, U_{L}} \in$ ]$c_{L}, c_{H}\left[\right.$. Therefore $\Pi_{L}=\frac{1}{b} \frac{s_{L}}{2}\left[\frac{c_{H}}{s_{H}}-\frac{c_{L}}{s_{L}}\right]\left[\frac{1}{2}\left(\frac{c_{H}-c_{L}}{s_{H}-s_{L}}+\frac{c_{H}}{s_{H}}\right)-\frac{1}{2}\left(\frac{c_{L}}{s_{L}}+\frac{c_{H}}{s_{H}}\right)\right]=$ 


$$
\frac{s_{L}}{4 b}\left[\frac{c_{H}}{s_{H}}-\frac{c_{L}}{s_{L}}\right]\left[\frac{c_{H}-c_{L}}{s_{H}-s_{L}}-\frac{c_{L}}{s_{L}}\right]
$$

The market segment served by the $H$-firm is $b-\frac{c_{H}-p_{L}}{s_{H}-s_{L}}=b-\frac{2 c_{H}--c_{L}-\frac{s_{L}}{s_{H}} c_{H}}{2\left(s_{H}-s_{L}\right)}=$ $b-\frac{c_{H}--c_{L}+\left(1-\frac{s_{L}}{s_{H}}\right) c_{H}}{2\left(s_{H}-s_{L}\right)}=b-\frac{1}{2}\left[\frac{c_{H}-c_{L}}{s_{H}-s_{L}}+\frac{c_{H}}{s_{H}}\right]$.

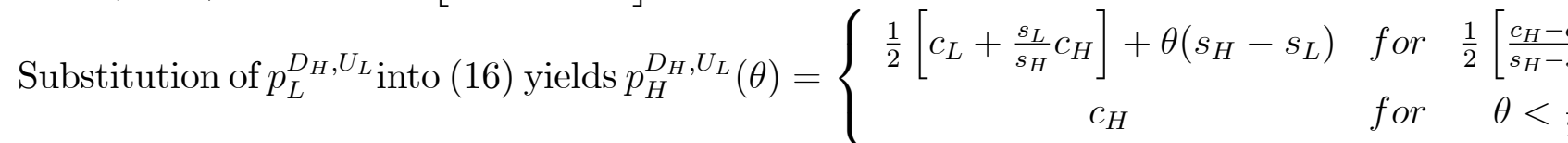

The average profit margin of the $H$-firm over the segment it serves is

$$
\begin{aligned}
& \frac{1}{2}\left(p_{H}^{D_{H}, U_{L}}(b)-c_{H}\right)=\frac{1}{2}\left[\frac{1}{2}\left(c_{L}+\frac{s_{L}}{s_{H}} c_{H}\right)+b\left(s_{H}-s_{L}\right)-c_{H}\right] \\
& \quad=\frac{s_{H}-s_{L}}{2}\left[b-\frac{c_{H}-c_{L}}{2\left(s_{H}-s_{L}\right)}-\frac{s_{H}-s_{L}}{2\left(s_{H}-s_{L}\right)} \frac{c_{H}}{s_{H}}\right]=\frac{s_{H}-s_{L}}{2}\left[b-\frac{1}{2}\left(\frac{c_{H}-c_{L}}{\left(s_{H}-s_{L}\right)}+\frac{c_{H}}{s_{H}}\right)\right] . \text { Thus, }
\end{aligned}
$$

the profit of the $H$-firm is $\Pi_{H}\left(D_{H}, U_{L}\right)=\frac{s_{H}-s_{L}}{2 b}\left[b-\frac{1}{2}\left(\frac{c_{H}-c_{L}}{\left(s_{H}-s_{L}\right)}+\frac{c_{H}}{s_{H}}\right)\right]^{2}$.

When $p_{L} \geq c_{H}$, the $H$-firm sells to all consumers with $\theta \in\left[\frac{c_{H}}{s_{H}}, b\right]$ for a price $p_{H}(\theta)=\theta s_{H}$. No consumer with $\theta \in\left[\frac{c_{L}}{s_{L}}, \frac{c_{H}}{s_{H}}\right]$ is willing to purchase low quality product at the uniform price $p_{L} \geq c_{H}$. More pointedly, when $p_{L} \geq c_{H}$, the high quality producer has a monopoly position and the low quality producer has no market at all. Therefore, choosing $p_{L} \geq c_{H}$ is never rational on the part of a leader who produces the low quality.

\subsubsection{Regime $\left(U_{H}, U_{L}\right)$}

This is the standard case examined in the literature [Gabszewicz and Thisse (1979), Shaked and Sutton (1982), Moorthy (1988, 1991)]. Profit functions are $\Pi_{H}\left(p_{H}, p_{L}\right)=\frac{1}{b}\left(p_{H}-c_{H}\right)\left(b-\frac{p_{H}-p_{L}}{s_{H}-s_{L}}\right)$ and $\Pi_{L}\left(p_{H}, p_{L}\right)=\frac{1}{b}\left(p_{L}-\right.$ $\left.c_{L}\right)\left(\frac{p_{H}-p_{L}}{s_{H}-s_{L}}-\frac{p_{L}}{c_{L}}\right)$. Simultaneous choice of prices by each firms yields $p_{H}^{U_{H}, U_{L}}=$ $\frac{s_{H}}{4 s_{H}-s_{L}}\left[2 b\left(s_{H}-s_{L}\right)+2 c_{H}+c_{L}\right]$ and $p_{L}^{U_{H}, U_{L}}=\frac{1}{4 s_{H}-s_{L}}\left[b s_{L}\left(s_{H}-s_{L}\right)+2 c_{L} s_{H}+\right.$ $\left.c_{H} s_{L}\right]$

Substitution into the profit function yields the profits that appear in Table 1 .

Appendix 3: Proof of the lemma.

The inequality $\Pi_{H}\left(D_{H}, D_{L}\right)=\frac{s_{H}-s_{L}}{2 b}\left[b-\frac{c_{H}-c_{L}}{s_{H}-s_{L}}\right]^{2}>\Pi_{H}\left(U_{H}, U_{L}\right)=\frac{4 s_{H}^{2}\left(s_{H}-s_{L}\right)}{\left(4 s_{H}-s_{L}\right)^{2} b}[b-$ $\left.\frac{1}{2}\left(\frac{c_{H}-c_{L}}{s_{H}-s_{L}}+\frac{c_{H}}{s_{H}}\right)\right]^{2}$

$=\frac{4 s_{H}^{2}\left(s_{H}-s_{L}\right)}{\left(4 s_{H}-s_{L}\right)^{2} b}\left[b-\frac{c_{H}-c_{L}}{s_{H}-s_{L}}+\frac{1}{2}\left(\frac{c_{H}-c_{L}}{s_{H}-s_{L}}-\frac{c_{H}}{s_{H}}\right)\right]^{2}$ is equivalent to $b-\frac{c_{H}-c_{L}}{s_{H}-s_{L}}>$ 


$$
\begin{aligned}
& \frac{2 \sqrt{2} s_{H}}{4 s_{H}-s_{L}}\left[b-\frac{c_{H}-c_{L}}{s_{H}-s_{L}}+\frac{1}{2} \frac{s_{L}}{s_{H}}\left(\frac{c_{H}-c_{L}}{s_{H}-s_{L}}-\frac{c_{L}}{s_{L}}\right)\right] \text { or } \\
& {\left[b-\frac{c_{H}-c_{L}}{s_{H}-s_{L}}\right]\left[1-\frac{2 \sqrt{2} s_{H}}{4 s_{H}-s_{L}}\right]>\sqrt{2} \frac{s_{H}}{4 s_{H}-s_{L}} \frac{s_{L}}{s_{H}}\left[\frac{c_{H}-c_{L}}{s_{H}-s_{L}}-\frac{c_{L}}{s_{L}}\right] . \text { Thus }} \\
& \quad \Pi_{H}\left(D_{H}, D_{L}\right)>\Pi_{H}\left(U_{H}, U_{L}\right) \Leftrightarrow \lambda>F_{H}(\alpha)=\frac{\sqrt{2} \alpha}{4-2 \sqrt{2}-\alpha}
\end{aligned}
$$

Because $\Pi_{L}\left(D_{H}, D_{L}\right)=\frac{s_{L}}{2 b}\left[\frac{c_{H}-c_{L}}{s_{H}-s_{L}}-\frac{c_{L}}{s_{L}}\right]\left[\frac{c_{H}}{s_{H}}-\frac{c_{L}}{s_{L}}\right]=\frac{s_{L}\left(s_{H}-s_{L}\right)}{2 b s_{H}}\left[\frac{c_{H}-c_{L}}{s_{H}-s_{L}}-\frac{c_{L}}{s_{L}}\right]^{2}$ and $\left.\Pi_{L}\left(U_{H}, U_{L}\right)=\frac{4 s_{L} s_{H}\left(s_{H}-s_{L}\right)}{\left(4 s_{H}-s_{L}\right)^{2} b}\left[\frac{1}{2}\left(b+\frac{c_{H}-c_{L}}{s_{H}-s_{L}}\right)-\frac{c_{L}}{s_{L}}\right)\right]^{2}$ we have $\Pi_{L}\left(D_{H}, D_{L}\right)>$ $\Pi_{L}\left(U_{H}, U_{L}\right)$ if and only if $\frac{c_{H}-c_{L}}{s_{H}-s_{L}}-\frac{c_{L}}{s_{L}}<\frac{2 \sqrt{2} s_{H}}{4 s_{H}-s_{L}}\left[\frac{1}{2}\left(b-\frac{c_{H}-c_{L}}{s_{H}-s_{L}}\right)+\left(\frac{c_{H}-c_{L}}{s_{H}-s_{L}}-\frac{c_{L}}{s_{L}}\right)\right]$ or

$$
\left(\frac{c_{H}-c_{L}}{s_{H}-s_{L}}-\frac{c_{L}}{s_{L}}\right)\left(1-\frac{2 \sqrt{2} s_{H}}{4 s_{H}-s_{L}}\right)<\frac{\sqrt{2} s_{H}}{4 s_{H}-s_{L}}\left(b-\frac{c_{H}-c_{L}}{s_{H}-s_{L}}\right)
$$

Thus

$$
\Pi_{L}\left(D_{H}, D_{L}\right)>\Pi_{L}\left(U_{H}, U_{L}\right) \Leftrightarrow \lambda<F_{L}(\alpha)=\frac{4-2 \sqrt{2}-\alpha}{\sqrt{2}}
$$

